\title{
Proceeding
}

Supplementary Issue: Spring Conferences of Sports Science. Costa Blanca Sports Science Events, 14-15 June 2019. Alicante, Spain.

\section{Physical-technical conditions, coaching and nutrition: An integrated approach to promote cohesion in sports team}

\author{
VALERIA DI ONOFRIO1 ${ }^{1}$, PIETRO MONTESANO², FILOMENA MAZZEO1 \\ ${ }^{1}$ Department of Science and Technology, University of Naples Parthenope, Naples, Italy \\ ${ }^{2}$ Department of Sport Sciences and Wellness, University of Naples Parthenope, Naples, Italy
}

\begin{abstract}
The aim was verified that the level of cohesion of a sports group is conditioned by numerous variables, which affect the athletes performance and lead to difficulties in adults relationships. The sample physical-technical and nutritional conditions and the help for the cohesion of a technique such as coaching were evaluated. Coaching can understand as the process in which individuals, mostly athletes, supported for their improvement and development in order to achieve performance high levels. 40 adults, aged between 35 and 45 years old, practicing football at amateur level for eight months, belonging to two different sports groups (blue and red group), have been observed. The results showed about $2.5 \%$ increase for blue group in Cooper test and about 1\% in Sargent test, while for red group the improvement was approximately 1.5\% in Cooper test and about $0.5 \%$ in Sargent test. 37 athletes correctly followed the nutrition specialists indications while 3 athletes showed negative responses. The personalized diets success confirmed by the decrease, in terms of $\mathrm{kg}$, of the average percentage of athletes' body weight. All sample highlighted, with the answers to the 14 items of the questionnaire, significant percentage variations in lifestyles and relationships between group members. Keywords: Cohesion; Nutrition lifestyles; Coaching; Team; Sport.
\end{abstract}

\section{Cite this article as:}

Di Onofrio, V., Montesano, P., \& Mazzeo, F. (2019). Physical-technical conditions, coaching and nutrition: An integrated approach to promote cohesion in sports team. Journal of Human Sport and Exercise, 14(4proc), S981-S990. doi:https://doi.org/10.14198/jhse.2019.14.Proc4.60

Corresponding author. University of Naples Parthenope, Department of Science and Technology, Business District, Block C4, 80143 Naples, Italy. https://orcid.org/0000-0001-9398-3496

E-mail: valeria.dionofrio@uniparthenope.it

Supplementary Issue: Spring Conferences of Sports Science. Costa Blanca Sports Science Events, 14-15 June 2019. Alicante, Spain.

JOURNAL OF HUMAN SPORT \& EXERCISE ISSN 1988-5202

(c) Faculty of Education. University of Alicante

doi:10.14198/jhse.2019.14.Proc4.60 


\section{INTRODUCTION}

The epistemological paradigm of motor sciences clearly declines that the athlete's performance is the sum of innumerable variables that invest the whole personality of the individual, for which the objective of improving sports performance has been addressed not only on the physical and technical aspects but also on psychological, organic and climatic ones. The custom to anticipate more and more, in terms of age, the times of sports specialization and the increasingly evident manifestation of performance anxiety not only has revealed by professional athletes, but also by normal subjects who practice physical activity, has focused the attention of the scholars on the many areas that can affect competitive performance. The aspects related to training systems, the quality of nutrition and the possibility of resorting to techniques of personal and collective support are those that, from observation and from the approach to existing literature, appear to have greater impact on the performances and on the cohesion of the sports group (Montesano \& Mazzeo, 2019).

The application, the repetitiveness, the development of new training methods can be assisted by techniques such as coaching which, in general, help to understand the complexities and experiences faced daily by any individual (coaches, athletes, parents, doctors, health workers) (Bush, Silk, 2010; Montesano \& Mazzeo, 2018 ). In fact, coaching can be conceived as the process in which individuals, mostly athletes, are supported for their improvement and development in order to achieve high levels of performance (ICCE, 2012). The latter, which take on different connotations depending on the components that influence their effectiveness, can be improved by acting synergistically to implement the cohesion of sports teams.

Cohesion is the process that implies the propensity in a group to form a bond to satisfy the performance objectives and the affective needs of the members (Carron, Colman, Wheeler, 2002). The cohesion of the team, which involves social components and tasks, represents the degree to which each member of a group collaborates to achieve goals, both personal and group, of high performance. The concept of cohesion is characterized by a dynamic, multidimensional and affective nature and depends on the individual attraction towards the group and the individual perception of the group as an integrated system (Carron, Widemeyer, Brawley, 1985). A meta-analytical study on the subject showed that social cohesion linked to the performance of the sports team is positively stronger than operational cohesion, confirming the belief reported by coaches that solidarity and unity linked to cohesion are significant predictive factors of a good performance (Carron, Colman, Wheeler, 2002).

\section{The contexts for the development of cohesion}

Cohesion is a dynamic process that reflects the tendency of members of a group to pursue the same goals while remaining united and establishing effective interpersonal relationships. Naturally within the group dynamics of a cooperative / oppositional conflict type are determined which are characterized by cohesive types of defensive type, with aggressiveness poured mainly out of the group, of an institutional type, with rigid rules that help to overcome conflicts, and of type cooperative with awareness and analysis of difficulties.

Cohesion is often identified as a simple relationship of friendship but in a group it is important to verify the task orientation to reach a clear and stimulating goal that is shared by all members. Recent studies have investigated factors such as cohesion (Aoyagi, Cox, McGuire, 2008; Murray, 2006; Turman 2003; Carron, Bray, Eys, 2002; Gammage, Carron, Estabrooks, 2001; Spink, 1995), which can influence the performance of sports teams suggesting appropriate management with effective techniques (Hoffmann, Loughead, 2016a; Fairhurst, Bloom, Harvey, 2016; McQuade, Davis, Nash, 2015). In the literature on different organizational contexts the concept of cohesion has been associated with better performance (Lurey, Raisinghani, 2001; Maznevski, Chudoba, 2000) and greater satisfaction (Chidambaram, 1996) and some studies emphasize 
that sports teams with greater cohesion achieve better results compared to less cohesive sports teams (Carron, Colman, Wheeler, 2002).

The reflection on the problems of cohesion in sports groups has resulted in the survey of a sample of 40 adult subjects aged between 35 and 45 practicing amateur sports for a period of eight months. Amateur athletes, belonging to two different sports groups, have performed a training and a race a week, were trained by specialized technicians and paid limited attention to their diet.

The study has been conducted, with surveys at the beginning and the end of the work path, implementing two monthly training sessions in addition to the four normally performed, regulating the diet with a nonpersonalized diet but compatible with sporting commitment and with the administration of a questionnaire.

\section{Nutrition and sport}

Nutritional status has a fundamental role to optimize the performance of competitive athletes, but not only (American College of Sports Medicine, 2000). In the world of sports, athletes and coaches underline the importance of a healthy and balance diet for both improving health and performance (Mazzeo et al.,2018). Diet, training capacity and functional demands also directly influence sports competition, especially at high levels. Nutrition is one of the factors that most contributes to the realization of an optimal physical form, a necessary precondition for achieving maximum sports performance (American College of Sports Medicine, 2000). Sports activity must be supported from a dietary point of view by providing, through food, molecules useful for performing physiological functions, promoting an increase in muscle mass and optimizing physical work by replenishing losses due to physical and mental stress (Mazzeo, 2016; Montesano et al., 2013). The effectiveness of the diet depends on the adequacy of the energy intake, its composition in nutrients and the modulation of the nutritional intake in the various phases of the sports program: athletic preparation, competition and recovery. There is no food that, on its own, is able to provide all the nutritional substrates necessary to deal with training or sports competition with commitment, but a healthy and adequate diet can effectively contribute to this (Giampietro, 2009).

The sportsman's diet must, first of all, ensure a supply of energy, in the form of calories, sufficient to cover energy needs, sometimes even very high, linked to sports. Secondly, it must meet the athlete's nutritional needs in order to promote and preserve a high level of psychophysical well-being, essential for obtaining adequate results in any sport. The nutrition of the sportsman must try to adequately distribute the food ration, sometimes greater than $5000 \mathrm{Kcal}$, during the day trying to meet the needs related to training or competition, through a balanced diet from a point of view of macro and micronutrients.

Not all athletes have high energy requirements: they may be necessary in sports such as skiing, swimming, canoeing, both at the time of training and during the competition itself, but the same cannot be said for other disciplines. Therefore, even considering variables such as different ages and morphological characteristics among athletes, it is not surprising at all to note that extremely different daily energy supplies coexist in the world of sport. However, it should be pointed out that the general population tends to overestimate the real energy expenditure of the various sports activities. In this regard, various tables on energy expenditure or predictive equations proposed over the years by various authors tend to overestimate the energy cost of sports (Giampietro, 2009). An optimal diet must provide the necessary substrates to cover the Energy Requirement, characterized by the need for tissue repair and new synthesis of some macromolecules favouring growth (Table 1). 
Table 1. Percentage of nutritional components

\begin{tabular}{ccccc}
\hline Carbohydrates (\%) & Proteins (\%) & Lipids (\%) & Fruits (N./die) & Vegetables (N./die) \\
\hline $50-60$ & $15-20$ & $25-30$ & $2-3$ & $>2$ \\
\hline
\end{tabular}

There are variations in energy expenditure depending on the type of sport considered and differences are present depending on the level of sport practiced (Hawley, 1995). The recommended diet may be associated with food supplements that can be grouped into dietary supplements, ergogenic aids and sports foods (Mazzeo, 2016). Current concept of obesity. Sport Science, 9(2), 42-48. (. Most of the statistics in the literature report that over half of athletes use supplements and the use of one or more food supplements can reach the percentage of $88 \%$ so much that there is a wide range of different types and brands of products for nutritional supplementation. The range of food supplements includes vitamins, minerals, amino acids, fatty acids or other substances that can be taken in the form of pills, tablets, capsules, liquids.

\section{Coaching e sport}

Coaching, among the support techniques, is the one that has received the most attention also due to the acceptance that was given to it by the experts. In the application emerges the central figure of the coach or a coach who, in an internal organizational behavioural perspective, influences cohesion in sports groups, through the meditated use of appropriate techniques and strategies. Effective coaches tend to avoid injustices, embarrassment, isolation behaviours and they promote the establishment of interpersonal relationships, the direct attention and dedication of athletes, always emphasizing, however, respect for the rules and the quality of the opponents (Turman, 2003).

The effective leadership of coaches (Chelladurai and Riemer 1998) and the interactional behavioural processes between coach and athletes, which influence team members towards performance, is positively correlated to the sense of belonging of the athletes to the team, therefore to cohesion.

In particular, a comparison of coaching leadership styles shows that football coaches, who have higher levels of training and education, social support, positive feedback, democratic behaviour and low levels of autocratic behaviour, increase the perception of athletes than to team cohesion: successful soccer teams tend to be more cohesive when their coaches show higher levels of democratic behaviour and social support. Interdependence in team sports, managed through effective driving behaviour, supports the significant need for cohesion that contributes to the team's success (Ramzaninezhad, Keshtan, 2009).

During last ten years, researches conducted in the field of effectiveness in conducting training has been based, mainly, on identifying the most effective coaching characteristics, leadership styles and interpersonal behavioural patterns and dynamics. Effective coach has been defined like a dynamic process that determines successful performance results and elicits positive psychological responses from its athletes (Horn, 2002). In fact, since coaches influence not only the physical performance of their athletes, but also their psychosocial well-being, it is important for an effective coach to give attention and take care of the personal and individual needs of their athletes.

Effective coaches must be aware of the fact that they can positively affect the team's performance by improving their coaching skills, mainly by observing themselves and understanding the effect their behaviour can have on athletes (Anshel, 2003).

The effectiveness of coaching has been the matter of several researches that have determined some models inspired by different perspectives. The social and institutional macro (Payne, Reynolds, Brown, Fleming, 
2003) identifies the criteria relating to the dynamic aspects of coaches' impact on social cohesion processes while that of coaching effectiveness (Horn, 2002) is inspired by the multidimensional model (Chelladurai, 1990) and to that of meditational leadership (Smoll, Smith, 1989).

Analysing the model of coaching effectiveness, it is clear that cohesion has a significant effect on the success of the team, regardless of the sport practiced (Ramzaninezhad, Keshtan, 2009) and without neglecting the question related to the question whether cohesion affects success and on performance, or success influences cohesion. It may be reasonable to assume that, as a team is more successful, the high level of performance is what makes one perceive a higher level of cohesion. Success has the potential to allow the development of strong interpersonal relationships and motivational drives.

Team sports cohesion (Carron et al., 1985; Brawley, 1990) is based on significant elements such as leadership, situational factors, personal factors and team factors and is embodied in individual and group results. For the effectiveness of coaching, in addition to the technical skills of the sport of reference, an effective coach may be required to occupy many roles in the life of their athletes (Anshel, 2003).

Coaching focuses on skills development and performance improvement, but at the same time pays attention to maintaining great control over the direction of the relationship (Clutterbuck, 2004). Coaches therefore play an invaluable role in the development of sports teams but, by becoming or supported by mentors, they can be more effective especially in fostering the necessary high team cohesion. Coaching was conceived as a process of guided improvement and development in a single sport in identifiable stages of athlete development (ICCE, 2012) and is focused on skills and performance related to specific tasks (Megginson, Clutterbuck, 1995). The concept of coaching is therefore correlated with the improvement of performance and the variation of people's learning needs (coacher / learner) (Leidl, 2009).

\section{METHODS}

A sample of 40 adult subjects, aged between 35 and 45 (Table 1) practicing soccer at an amateur level are enclosed in the research. They were enrolled for a period of eight months, belonging to two different sports groups, called blue (blue group) and red (red group) in line with the colour of the respective game uniforms, which carried out a training and a competition a week, trained by specialized technicians and paid limited attention to their feeding. The sample has been also chosen on the basis of the reflection on the relationship and collaboration difficulty that occurs in adulthood, given that the adult subject, compared to the young, lives the amateur sports experience as a challenging but stress-relieving moment daily in which family and work commitments and social difficulties occupy most of the time available.

Table 2. Average height and weight of the athletes

\begin{tabular}{ccccccc}
\hline & $\begin{array}{c}\text { Average } \\
\text { height }\end{array}$ & $\begin{array}{c}\text { Average } \\
\text { height }\end{array}$ & $\begin{array}{c}\text { Initial Average } \\
\text { weight }\end{array}$ & $\begin{array}{c}\text { Final Average } \\
\text { weight }\end{array}$ & $\begin{array}{c}\text { Initial Average } \\
\text { weight }\end{array}$ & $\begin{array}{c}\text { Final Average } \\
\text { weight }\end{array}$ \\
& $(\mathrm{Cm})$ blue & $(\mathrm{Cm})$ red & $(\mathrm{Kg})$ blue & $(\mathrm{Kg})$ blue & $(\mathrm{Kg})$ red & $(\mathrm{Kg})$ red \\
& group & group & group & group & group & group \\
\hline Total & $178+/-6$ & $175+/-5$ & $77+/-7$ & $74,5+/-5$ & $75+/-7$ & $73+/-6$ \\
\hline
\end{tabular}

To the athletes has been given, in the initial and final phase, the Cooper test and the Sargent test by the technical staff of the two groups, coordinated by the research team, and the answers to the items of the questionnaire (Table 2) administered to detect the level of group cohesion. 
At the end of the period, the correct intake of the recommended foods in a broad-spectrum diet, including personal needs (regularity of schedules, of hired meals, etc.), has been verified, giving attention in the first fifteen days to the activities aimed and to the correct eating habits and the importance of sports activity.

Table 3. Survey

\begin{tabular}{|c|c|c|}
\hline Items & Little & Quite \\
\hline 1 & In your opinion, how important is it to practice sports? & \\
\hline 2 & $\begin{array}{l}\text { In your opinion, how important is an eating style for an } \\
\text { athlete? }\end{array}$ & \\
\hline 3 & In your opinion, how correct is your nutritional style? & \\
\hline 4 & $\begin{array}{l}\text { In your opinion it is correct to include carbohydrates in the } \\
\text { diet? }\end{array}$ & \\
\hline 5 & In your opinion it is correct to include sugars in the diet? & \\
\hline 6 & In your opinion it is correct to include lipids in the diet? & \\
\hline 7 & In your opinion it is correct to include proteins in the diet? & \\
\hline 8 & The climate within your sports group is peaceful? & \\
\hline 9 & The climate within your sports group is collaborative? & \\
\hline 10 & The climate within your sports group is friendly? & \\
\hline 11 & The climate within your sports group is one of indifference? & \\
\hline 12 & Consider using effective support methods such as coaching? & \\
\hline 13 & Consider the relationship within the group effective? & \\
\hline 14 & Consider training methods effective? & \\
\hline
\end{tabular}

To the participants has been offered, in addition to the single weekly training session, two additional monthly sports sessions, for a total of 12 total sessions, whose contents were inspired by the concept of work in progress, with the organization of work in circuits and simulating also competitions in other disciplines such as basketball (Montesano 2016) and handball (Montesano, 2018). During the research period the working time has been progressively increased, from 30-45 min to 55-70 min, and the intensity of the activity. The performance of a standard session included low intensity for at least the first fifteen minutes, with a constant and training heart rate and a continuous and regular oxygenation, so that aerobic training, in addition to the direct consumption of fat, induced positive changes in the basal metabolism; greater resistance in everyday activities; a greater capacity for recovery after every type of effort; an increased blood supply throughout the body; a regularization of blood pressure; a regularization of the pulse frequency. The exercises have been carried out both at free load and with isokinetic tools and equipment as well as medicinal balls, ballasted anklets, etc. The supplementary sessions, for each group, have been attended by a pedagogist with the functions of tutor to facilitate the development of the coaching process.

\section{RESULTS}

The data collected by the research team has been processed at the end of the research period. For the blue group, the final analysis showed an increase of about $2.5 \%$ in the Cooper test and about $1 \%$ in the Sargent test, while for the red group the improvement was around 1.5\% in the Cooper test is about $0.5 \%$ in the Sargent test. The verification for food intake has showed that thirty-seven athletes correctly followed the indications of the nutrition specialists, while for only three athletes, two from the blue group and one from the red group, injuries has been discontinued due to injuries (two cases) and a persistent fluency that has limited 
usability for three weeks. The observance of the nutritional indications is confirmed by the decrease, in terms of $\mathrm{Kg}$., of the average percentage of the body weight of the athletes (Table 2).

The answers, in percentage form, to the 14 items of the questionnaire showed significant changes relating to lifestyles and relationships between group members.

Table 4. Initial and final results of the questionnaire replies

\begin{tabular}{clccccc}
\hline & Initial & & & & Final \\
\hline$\%$ & $\%$ & $\%$ & & $\%$ & $\%$ & $\%$ \\
\hline $\mathrm{L}$ & $\mathrm{Q}$ & $\mathrm{V}$ & ITEMS & $\mathrm{L}$ & $\mathrm{Q}$ & $\mathrm{V}$ \\
\hline & & 100 & $\mathbf{1}$ & & & 100 \\
\hline & 36 & 64 & $\mathbf{2}$ & & 17 & 83 \\
\hline 18 & 62 & 20 & $\mathbf{3}$ & 54 & 39 & 7 \\
\hline & 34 & 46 & $\mathbf{4}$ & & 42 & 58 \\
\hline & 48 & 52 & $\mathbf{5}$ & & 49 & 51 \\
\hline 34 & 38 & 28 & $\mathbf{6}$ & 49 & 42 & 9 \\
\hline 23 & 54 & 23 & $\mathbf{7}$ & 23 & 62 & 17 \\
\hline 8 & 44 & 48 & $\mathbf{8}$ & 8 & 44 & 48 \\
\hline 18 & 43 & 39 & $\mathbf{9}$ & 5 & 52 & 43 \\
\hline 56 & 29 & 15 & $\mathbf{1 0}$ & 18 & 48 & 34 \\
\hline 65 & 32 & 3 & $\mathbf{1 1}$ & 68 & 33 & 2 \\
\hline & 34 & 66 & $\mathbf{1 2}$ & & 30 & 70 \\
\hline & 46 & 54 & $\mathbf{1 3}$ & & 47 & 53 \\
\hline 5 & 59 & 36 & $\mathbf{1 4}$ & 5 & 54 & 41 \\
\hline
\end{tabular}

\section{DISCUSSION AND CONCLUSION}

The research has confirmed that the detection of cohesion in groups, and in particular in sports groups, is effective if the survey is developed at a systemic level (Mazzeo et al., 2016). The choice of areas of intervention has been made considering the variables of the athletes' competitive performance.

At the physical-technical level the performance can be verified with the comparison of the results of the motor tests as well as with the performances in the race. Indicators of the change in nutritional style are the change in body weight and the choice of the most suitable foods for a diet suitable for sportsmen.

The cohesion of the group, the relationship, the collaboration are underestimated and, often, underestimated in the final balance concerning the performance of a single athlete and a team. The purpose, explained with the administration of the questionnaire, has been to demonstrate that the synergy of intervention in several areas may produce positive effects.

While verifying the lack of literature on sports coaching, it is necessary for coaches to be more effective in fostering the cohesion of sports groups by supporting the needs of athletes also by improperly providing psychological and sociological functions. 
The systemic approach, however, brought out the value of the coaching function as well as the development of the themes of collaboration, through the proposals of unexpected game situations and the related solution strategies, which raise the level of relationship and of cohesion.

\section{REFERENCES}

American College of Sports Medicine, American Dietetic Association, Dietitians of Canada (2000). Joint Position Statement: nutrition and athletic performance. Med. Sci. Sports Exerc, 32(12): 2130-45. https://doi.org/10.1016/i.jada.2009.01.005

Anshel, M.H. (2003). Sport Psychology: from Theory to Practice. (4th edition), San Francisco, CA: Benjamin Cummings.

Aoyagi, M.W., Cox, R.H., McGuire, R.T. (2008). Organizational citizenship behavior in sport: Relationships with leadership, team cohesion, and athlete satisfaction. Journal of Applied Sport Psychology, 20 (1): 25-41. https://doi.org/10.1080/10413200701784858

Brawley, L. R. (1990). Group Cohesion: Status, Problems, and Future Directions. International Journal of Sport Psychology, 21: 355-379.

Brawley, L., Carron, A., Widmeyer, W. (1993). The influence of the group and its cohesiveness on perceptions of group-related variables. Journal of Sport \& Exercise Psychology, 15: 245-260. https://doi.org/10.1123/isep.15.3.245

Bush, A., Silk, M. (2010). Towards an evolving critical consciousness in coaching research: The physical pedagogic bricolage. International journal of sports science \& coaching, 5: 551-565. https://doi.org/10.1260/1747-9541.5.4.551

Carron, A.V., Bray, S.R., Eys, M.A. (2002). Team cohesion and team success in sport. Journal of Sports Sciences, 20: 119-126. https://doi.org/10.1080/026404102317200828

Carron, A.V., Colman, M.M., Wheeler, J. (2002). Cohesion and performance in sport: A meta-analysis. Journal of Sport \& Exersice Psychology, 24: 168-188. https://doi.org/10.1123/jsep.24.2.168

Carron, A.V., Widemeyer, W.N., Brawley L.R. (1985). The development of an instrument to assess cohesion in sport teams: The Group Environment Questionnaire. Journal of Sport Psychology, 7: 244-266. https://doi.org/10.1123/isp.7.3.244

Chelladurai, P. (1990). Leadership in sports, A Review. International Journal of Sport Psychology, 21 : 328-354.

Chidambaram, L. (1996). Relational development in computer-supported groups. MIS quarterly, 143165. https://doi.org/10.2307/249476

Clutterbuck, D. (2004). Everyone needs a mentor: Fostering talent in your organisation. CIPD Publishing.

Fairhurst, K.E., Bloom, G.A., Harvey, W.J. (2016). The learning and mentoring experiences of Paralympic coaches. Disability and Health Journal, 1-7. https://doi.org/10.1016/i.dhjo.2016.10.007

Giampietro M. "L'alimentazione, l'esercizio fisico e lo sport". II Pensiero Scientifico Editore. 2009.

Hawley JA. et al. (1995). "Nutritional practices of athletes: are they sub-optimal?", J Sports Sci, S75-81.

Hoffmann, M.D., Loughead, T.M. (2016b). A comparison of well-peer mentored and non-peer mentored athletes' perceptions of satisfaction. Journal of sports sciences, 34 (5): 450-458. https://doi.org/10.1080/02640414.2015.1057517

Horn, T. S. (2002). Coaching Effectiveness in the Sport Domain. In Horn, T.S. (Ed.), Advances in Sport Psychology, Champing, IL: Human Kinetics, 309-355.

International Council for Coaching Excellence, (ICCE). (2012). International sport coaching framework. Version 1.1 Human Kinetics. Champaign, IL. 
Leidl, D. (2009). Motivation in sport: bridging historical and contemporary theory through a qualitative approach. International Journal of Sports Science \& Coaching, 4 (2): 155-175. https://doi.org/10.1260/174795409788549517

Lurey, J. S., Raisinghani, M. S. (2001). An empirical study of best practices in virtual teams. Information \& Management, 38 (8): 523-544. https://doi.org/10.1016/s0378-7206(01)00074-x

Lusher, D., Robins, G., Kremer, P. (2010). The application of social network analysis to team sports. Measurement in Physical Education and Exercise Science, 14 (4): 211-224. https://doi.org/10.1080/1091367x.2010.495559

Maznevski, M.L., Chudoba, K.M. (2000). Bridging space over time: Global virtual team dynamics and effectiveness. Organization science, 11 (5): 473-492. https://doi.org/10.1287/orsc.11.5.473.15200

Mazzeo, F., Santamaria, S., \& Montesano, P. (2019). Gender difference, nutritional supplements and drug use in sport to enhancing performance: An italian revision over the last decade. Sport Mont, 17(1): 69-73. https://doi.org/10.26773/smi.190212

Mazzeo, F. (2016). Current concept of obesity. Sport Science, 9 (2): 42-48.

Mazzeo, F., Santamaria, S., Monda, V., Tafuri, D., Dalia, C., Varriale, L., De Blasio, S., Esposito, V., Messina, G., Monda, M. (2016). Dietary supplements use in competitive and non-competitive boxer: An exploratory study. Biology and Medicine, 8 (4). https://doi.org/10.4172/0974-8369.1000294

McQuade, S., Davis, L., Nash, C. (2015). Positioning mentoring as a coach development tool: Recommendations for future practice and research. Quest, 67 (3): 317-329. https://doi.org/10.1080/00336297.2015.1048810

Megginson, D., Clutterbuck, D. (1995). Mentoring in Action: A Practical Guide for Managers, Kogan Page, London.

Murray, N.P. (2006). The differential effect of team cohesion and leadership behavior in high school sports. Individual Differences Research, 4 (4): 216-225.

Montesano, P., \& Mazzeo, F. (2019). Sports activities in obese teenagers improve social inclusion and health. Sport Mont, 17(1): 55-60. https://doi.org/10.26773/smj.190210

Montesano P. (2016). Goalkeeper in soccer: performance and explosive strength. Journal of Physical Education and Sport@ (JPES), 16 (1): 230 - 233.

Montesano, P., \& Mazzeo, F. (2018). Pilates improvement the individual basics of service and smash in volleyball. Sport Mont, 16 (3): 25-30. https://doi.org/10.26773/smj.181005

Montesano P. (2018). Monitoring and upgranding of coordinative and conditional capacities of young athletes practicing handball. Journal of Physical Education and Sport, 18 (Suppl 1): 465-468.

Montesano, P., Tafuri, D., Esposito, A., Gigante, F., Salzano, E., Viscido, G., \& Mazzeo, F. (2013). Conditional abilities in young special olympics athletes who practice unified football. Journal of Physical Education and Sport, 13 (4): 504-510. https://doi.org/10.7752/jpes.2013.04079

Payne, W., Reynolds, M., Brown, S., Fleming, A. (2003). Sports Role Models and their Impact on Participation in Physical Activity: a Literature Review. Victoria: VicHealth. www.vichealth.vic.gov.au

Ramzaninezhad, R., Keshtan, M.H. (2009). The relationship between coach's leadership styles and team cohesion in Iran football clubs professional league. Brazilian Journal of Biomotricity, 3 (2): 111-120.

Smoll, F.L., Smith, R.E. (1989). Leadership Behaviors in Sport, A Theoretical Model and Research Paradigm. Journal of Applied Social Psychology, 19: 1522-1551. https://doi.org/10.1111/i.15591816.1989.tb01462.x

Spink, K.S. (1995). Cohesion and intention to participate of female sport team athletes. Journal of Sport and Exercise Psychology, 17 (4): 416-427. https://doi.org/10.1123/jsep.17.4.416

Turman, P.D. (2003). Coaches and cohesion: The impact of coaching techniques on team cohesion in the small group sport setting. Journal of Sport Behavior, 26 (1): 86-104. 


\section{(c) $($ ) $९$ EY}

This work is licensed under a Attribution-NonCommercial-NoDerivatives 4.0 International (CC BY-NC-ND 4.0). 